\title{
Thoracic interfascial nerve block for breast surgery in a pregnant woman
}

\section{-a case report-}

\author{
Boohwi Hong, Seok-Hwa Yoon, Ann Misun Youn, Bum June Kim, \\ Seunghyun Song, and Yeomyung Yoon \\ Department of Anesthesiology and Pain Medicine, Chungnam National University College of Medicine, Daejeon, \\ Korea
}

Regional anesthesia for non-obstetric surgery in parturients is a method to decrease patient and fetal risk during general anesthesia. Thoracic interfascial nerve block can be used as an analgesic technique for surgical procedures of the thorax. The Pecs II block is an interfascial block that targets not only the medial and lateral pectoral nerves, but also the lateral cutaneous branch of the intercostal nerve. Pecto-intercostal fascial block (PIFB) targets the anterior cutaneous branch of the intercostal nerve. The authors successfully performed a modified Pecs II block and PIFB without complications in a parturient who refused general anesthesia for breast surgery.

Key Words: Breast surgery, Parturient, Regional anesthesia.

The incidence of breast cancer during pregnancy is $1: 5,000$, but its treatment is no different from that in non-pregnant patients [1]. Pregnancy is not a contraindication for surgical resection, but general anesthesia for surgery is a stressful situation not only for the parturients but also for clinicians. Airway management of parturients is difficult, with a high incidence of awareness, preterm delivery, and intrauterine fetal asphyxia [2]. Fetal neurotoxicity and long-term neonatal neurocognitive effects

Corresponding author: Boohwi Hong, M.D.

Department of Anesthesiology and Pain Medicine, Chungnam National University College of Medicine, 282, Munhwa-ro, Jung-gu, Daejeon 35015, Korea

Tel: 82-42-280-7840, Fax: 82-42-280-7968

Email: koho0127@gmail.com

ORCID: http://orcid.org/0000-0003-2468-9271

Received: August 29, 2016.

Revised: October 19, 2016.

Accepted: October 24, 2016.

Korean J Anesthesiol 2017 April 70(2): 209-212

https://doi.org/10.4097/kjae.2017.70.2.209 due to anesthetics must also be considered [3]. For such reasons, regional anesthesia is recommended, if possible [4]. Pecs blocks are thoracic interfascial nerve blocks, targeting the cutaneous branches of the intercostal nerve and medial and lateral pectoral nerves $[5,6]$. During chest wall surgery, this type of nerve block is effective in controlling pain of somatic origin without the need to control pain of visceral origin. The authors report the case of a parturient (27 weeks) who refused to undergo general anesthesia for surgical removal of recurrent breast cancer and was given a modified Pecs II block and pecto-intercostal fascial block (PIFB) for analgesia.

\section{Case Report}

A 34-year-old parturient (27 weeks, $152.1 \mathrm{~cm} / 52.6 \mathrm{~kg}$, body mass index [BMI] 22.7) was presented with recurrent breast cancer. Past medical history revealed total mastectomy due to breast cancer 4 years earlier, and 6 cycles of chemotherapy. Drug therapy was discontinued two years previously due to pregnancy plans. The patient was very concerned both for herself and the fetus concerning general anesthesia, and our department was

(c) This is an open-access article distributed under the terms of the Creative Commons Attribution Non-Commercial License (http://creativecommons.org/ licenses/by-nc/4.0/), which permits unrestricted non-commercial use, distribution, and reproduction in any medium, provided the original work is properly cited. 
consulted for other anesthetic options. Wide excision 3-4 cm below the clavicle was scheduled, with resection just before the pectoralis major muscle. We planned modified a Pecs II block and PIFB and monitored anesthesia care.

Mylab $^{\mathrm{TM}} 25$ Gold (Esaote, Genova, Italy) and a linear probe (LA435: 6-18 MHz, Esaote) were used as the ultrasonographic equipment. We first performed a modified Pecs II block with the patient in a supine position with the arm in a neutral position. The probe was placed $1 / 3$ of the distance distal to the clavicle to identify anatomical landmarks, such as the pectoralis major and minor muscle, pectoral branch of the thoracoacromial artery, 2nd and 3rd ribs, and serratus anterior muscle (SAM). A 22-gauge Quincke spinal needle with diluted $0.3 \%$ ropivacaine was prepared to target the $2 \mathrm{nd} \mathrm{rib}$, and the needle was then inserted in a medial to lateral direction. After confirming the widening of the SAM and fascial plane of the rib, the drug was injected. As the SAM and external intercostal muscle widened along the fascial plane, the needle was relocated to the $3 \mathrm{rd} \mathrm{rib}$, and a total of $20 \mathrm{ml}$ of ropivacaine was injected (Fig. 1). The tip of the needle was placed between the pectoralis major and minor muscles by subtracting the needle, during which the pectoral branch of the throacoacromial artery was identified, and an additional $10 \mathrm{ml}$ of the drug was injected.

Afterward, we moved to the patient's right side to perform a PIFB. We scanned the right lateral border of the sternum to identify the 2 nd to 4 th costal cartilages, and, targeting the 4th costal cartilage, the needle was inserted. We confirmed the expansion of the pectoralis muscle and plane of the costal cartilage, and consecutively the pectoralis major muscle and plane

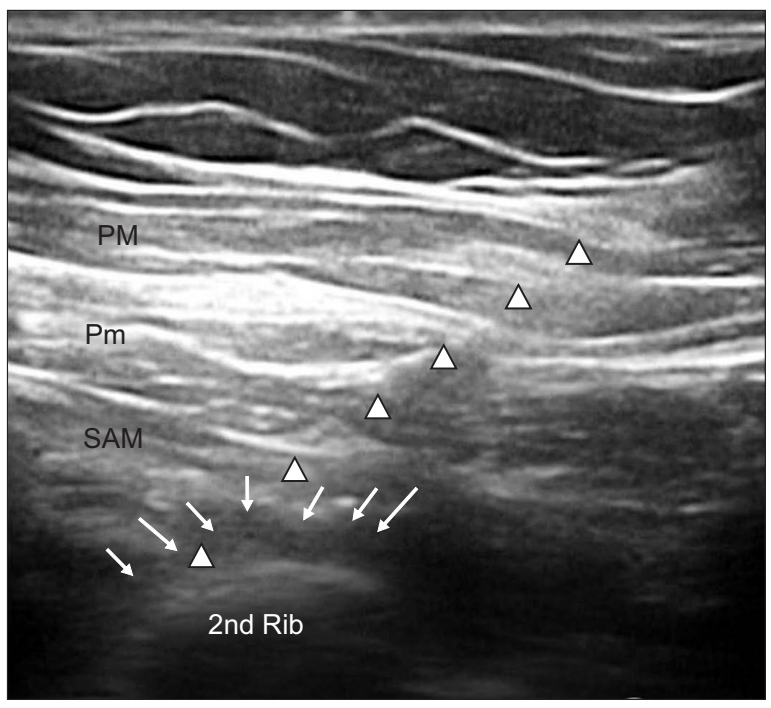

Fig. 1. Ultrasound image of 2nd injection of modified Pecs II block. Pectoralis major $(\mathrm{PM})$, pectoralis minor $(\mathrm{Pm})$, serratus anterior muscle (SAM), and 2nd rib are demonstrated. Local anesthetics were injected underneath PM (small arrows). Arrowhead: needle. of the external intercostal muscle. The needle was then carefully placed between the 2nd and 3rd costal cartilages and a total of $15 \mathrm{ml}$ of drug was injected while confirming expansion of the fascia plane (Fig. 2).

Approximately 10 minutes later, a spinal needle stylet was used to perform a pinprick test of the surgical area, and after confirmation of sensory loss, surgery was carried out. For anxiolysis, propofol $0.25 \mathrm{mg} / \mathrm{kg} / \mathrm{min}$ was administered, and the patient remained cooperative and tranquil (Ramsay Sedation Scale 2). During skin incision, wound retraction, and pectoralis

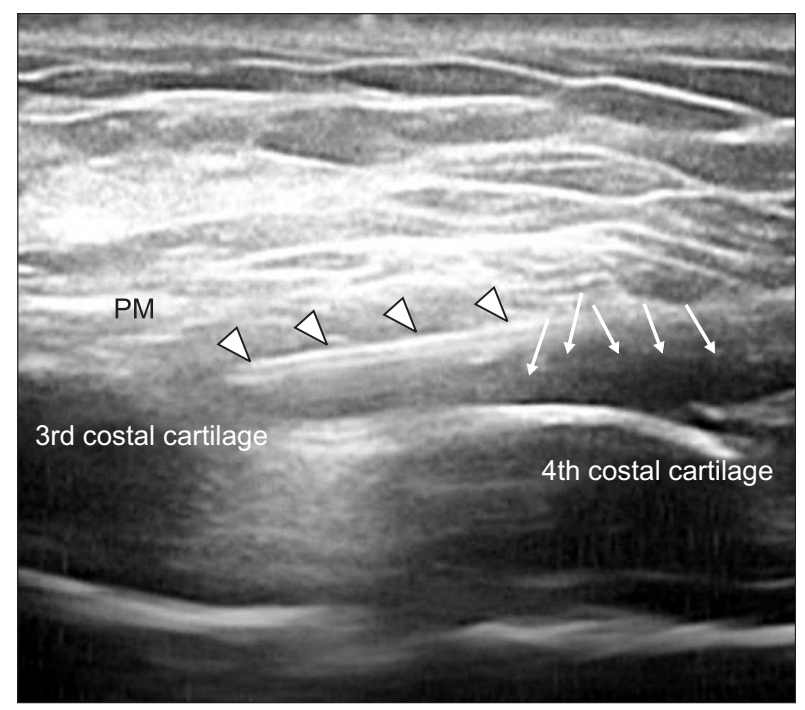

Fig. 2. Ultrasound image of pecto-intercostal fascial plane block. Pectoralis major (PM), 3rd and 4th costal cartilages are demonstrated. Needle was advanced in the cephalad direction while injecting local anesthetics underneath PM (small arrows), starting from 4th costal cartilage level. Arrowhead: needle.

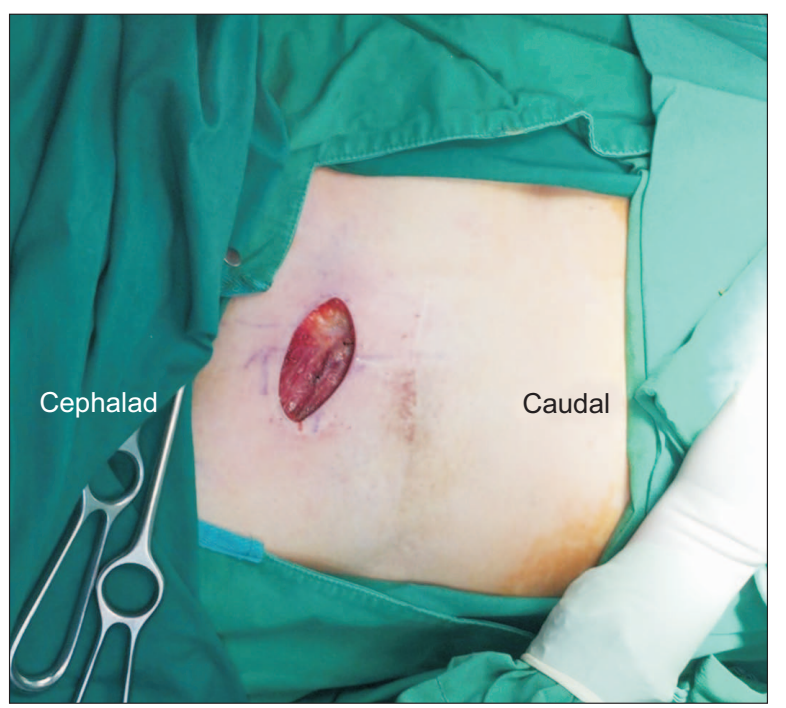

Fig. 3. Operation field. Wide excision performed with 5-6 cm incision. 
muscle bleeding control, the patient did not report pain or discomfort. However, when an upper incision toward the clavicle was made to confirm the upper margin of the mass, the patient did report discomfort. The total duration of surgery was 1 hour, including time spent waiting for biopsy results (Fig. 3). Postoperative visual analogue scale score was one, and the patient did not report pain during dressing of the surgical site or slight percussion from decreased sensation. The patient did not require additional analgesics, and sensation at the surgical site returned to normal the next day. Findings of follow-up fetal evaluations were nonspecific, and the patient was discharged on postoperative day 3 . The parturient is currently scheduled for cesarean section.

\section{Discussion}

The safety of the parturient and fetus is an important issue to consider in surgery and anesthesia during pregnancy. Nonobstetric surgery during pregnancy can lead to maternal death, miscarriage, elective termination, and preterm delivery. For the fetus, fetal death, prematurity, and major birth defects have been reported.

General and regional anesthesia can be performed successfully during non-obstetric surgery in parturients. Although the superiority of one or the other is controversial, regional anesthesia can avoid the potential risks of failed intubation and aspiration, in addition to reducing the exposure of the fetus to potential teratogens and providing excellent postoperative analgesia [5]. Adequate postoperative analgesia is fairly important, since pain has been shown to increase the risk of premature labor. Regional anesthesia can provide excellent postoperative analgesia and reduce the risk of opioid-induced hypoventilation when compared with intravenous opioids [6]. During general anesthesia, airway management in the parturient is further complicated by the anatomical changes related to both weight gain and edema of the upper airway and vocal cords, which occurs secondary to a generalized increase in capillary permeability. There is a significant risk of failed intubation and airway trauma during instrumentation.

In regional anesthesia, less systemic absorption of drugs occurs than during general anesthesia, and ropivacaine is classified as a Pregnancy Category B drug. Thus, regional anesthesia can be performed safely if the surgical area or surgical methods are appropriate.

Blanco [5] first introduced a Pecs block as a nerve block for breast surgery, in which, according to the combination of injection plane and location, it has been known by various names, such as Pecs block (I and II), serratus plane block, etc. [5-7] (Table 1). For a Pecs I block, the local anesthetic is injected between the pectoralis major and minor muscles at the level of the 3rd rib. For Pecs II block, in addition to the Pecs I block, a second injection is made on the anterior axillary line at the level of the 3rd or 4th rib above or below the SAM [8]. A serratus plane block is given more laterally and caudally on the midaxillary line at the level of the 5th rib where the latissimus dorsi muscle is located, and is injected above or below the SAM. Thoracic interfascial blocks can also be administered according to the clinical situation, and several modified approaches have been reported [9]. However, the anatomical target of these approaches is identical. For example, Fajardo's approach of serratus intercostal fascial block, which is performed below the SAM at the level of the 2nd rib [10,11], is actually identical to the 2 nd injection of the Pecs II block, and could also be described as a modified-Pecs II block. The PIFB consists of injecting a local anesthetic between the pectoralis major muscle and the external intercostal muscle, in the interfascial plane where the anterior cutaneous branch emerges from the lateral side of the sternum [12].

We performed the second injection of the Pecs II block at the level of the 2 nd rib below the SAM. The surgical dermatome was thought to be above T3. T2 is also more superficial than T3 on ultrasonography, which makes it easier to locate. Injecting below the SAM is unique, with excellent benefits of targeting the rib surfaces by hydrodissection and preventing pleural puncture when ultrasonographic images are inadequate. According to Pérez et al. [10], drug injection between the SAM and external intercostal muscle or the ribs can avoid blocking the long tho-

Table 1. Thoracic Interfascial Nerve Blocks

\begin{tabular}{|c|c|c|c|}
\hline Block & Target fascial plane & Target nerve & Volume of LA \\
\hline Pecs I & Between PM and Pm & Lateral and medial pectoral nerves & $10 \mathrm{ml}$ \\
\hline Pecs II & $\begin{array}{l}\text { Pecs I }+2 \text { nd injection } \\
\text { 2nd injection: above (between Pm and SAM) or } \\
\text { underneath SAM above 3rd rib }\end{array}$ & $\begin{array}{l}\text { Lateral and medial pectoral nerves (Pecs I) } \\
\text { Lateral branch of intercostal nerve (T2-T4) } \\
\text { (2nd injection) }\end{array}$ & $\begin{array}{l}10 \mathrm{ml}(\text { Pecs I })+ \\
20 \mathrm{ml}(\text { 2nd injection })\end{array}$ \\
\hline Serratus plane block & $\begin{array}{l}\text { Above (between ldm and SAM) or underneath } \\
\text { SAM above 5th rib }\end{array}$ & $\begin{array}{l}\text { Lateral cutaneous branch of intercostal nerve } \\
\text { (T2-T9) }\end{array}$ & $40 \mathrm{ml}$ \\
\hline PIFB & Underneath PM on lateral side of sternum & Anterior cutaneous branch of intercostal nerve & $2-3 \mathrm{ml} /$ dermatome \\
\hline
\end{tabular}

PIFB: pecto-intercostal fascial block, PM: pectoralis major muscle, Pm: pectoralis minor muscle, SAM: serratus anterior muscle, ldm: latissimus dorsi muscle, LA: local anesthetics. 
racic nerve located above the SAM.

PIFB was performed on the patient's right side, in a caudal to cranial direction. If analgesia after general anesthesia is the goal, PIFB may be performed with the patient's head turned away and injected cranial to caudal after Pecs II without the operator having to move from one side of the patient to the other.

This type of breast block may be inadequate in blocking the upper part of the breast, which is innervated by the supraclavicular nerve [13]. The authors contemplated performing a supraclavicular nerve block but decided to confirm the degree of block according to the dermatome after giving a Pecs II and PIFB. With sensory loss of the incision site confirmed, we allowed the surgery to proceed, which was why the patient re- ported discomfort during traction of the upper incision.

Thoracic interfascial block can be performed to resolve thoracic cage pain in patients in the intensive care unit [14] or to manage intractable post-thoracotomy syndrome [15], but reports of these blocks for anesthesia are limited. Thoracic interfascial block is an attractive alternative in cases in which general anesthesia is undesirable.

\section{ORCID}

Boohwi Hong, http://orcid.org/0000-0003-2468-9271

Ann Misun Youn, http://orcid.org/0000-0001-5491-5888

\section{References}

1. Melnick DM, Wahl WL, Dalton VK. Management of general surgical problems in the pregnant patient. Am J Surg 2004; 187: 170-80.

2. Heesen M, Klimek M. Nonobstetric anesthesia during pregnancy. Curr Opin Anaesthesiol 2016; 29: 297-303.

3. Flood P. Fetal anesthesia and brain development. Anesthesiology 2011; 114: 479-80.

4. Van De Velde M, De Buck F. Anesthesia for non-obstetric surgery in the pregnant patient. Minerva Anestesiol 2007; 73: $235-40$.

5. Blanco R. The 'pecs block': a novel technique for providing analgesia after breast surgery. Anaesthesia 2011; 66: 847-8.

6. Blanco R, Fajardo M, Parras Maldonado T. Ultrasound description of Pecs II (modified Pecs I): a novel approach to breast surgery. Rev Esp Anestesiol Reanim 2012; 59: 470-5.

7. Blanco R, Parras T, McDonnell JG, Prats-Galino A. Serratus plane block: a novel ultrasound-guided thoracic wall nerve block. Anaesthesia 2013; 68: 1107-13.

8. Blanco R. A reply. Anaesthesia 2014; 69: 1173-4.

9. Fuzier R. Yet more on Pecs block nomenclature. Anaesthesia 2015; 70: 508-9.

10. Pérez MF, Duany O, de la Torre PA. Redefining PECS blocks for postmastectomy analgesia. Reg Anesth Pain Med 2015; 40: 729-30.

11. Pérez MF, Miguel JG, de la Torre PA. A new approach to pectoralis block. Anaesthesia 2013; 68: 430.

12. de la Torre PA, García PD, Alvarez SL, Miguel FJ, Pérez MF. A novel ultrasound-guided block: a promising alternative for breast analgesia. Aesthet Surg J 2014; 34: 198-200.

13. Blanco R, Parras Maldonado T. Reply to the article entitled "Ultrasound description of Pecs II (modified Pecs I): a novel approach to breast surgery". Reply of the authors. Rev Esp Anestesiol Reanim 2013; 60: 296-7.

14. López-Matamala B, Fajardo M, Estébanez-Montiel B, Blancas R, Alfaro P, Chana M. A new thoracic interfascial plane block as anesthesia for difficult weaning due to ribcage pain in critically ill patients. Med Intensiva 2014; 38: 463-5.

15. Fujiwara S, Komasawa N, Minami T. Pectral nerve blocks and serratus-intercostal plane block for intractable postthoracotomy syndrome. J Clin Anesth 2015; 27: 275-6. 